\title{
Ion Trap Collision-Induced Dissociation of Locked Nucleic Acids
}

\author{
Teng-yi Huang, Anastasia Kharlamova, and Scott A. McLuckey \\ Department of Chemistry, Purdue University, West Lafayette, Indiana, USA
}

Gas-phase dissociation of model locked nucleic acid (LNA) oligonucleotides and functional LNA-DNA chimeras have been investigated as a function of precursor ion charge state using ion trap collision-induced dissociation (CID). For the model LNA 5 and 8 mer, containing all four LNA monomers in the sequence, cleavage of all backbone bonds, generating $\mathrm{a} / \mathrm{w}-, \mathrm{b} / \mathrm{x}-$, $c / y-$, and d/z-ions, was observed with no significant preference at lower charge states. Base loss ions, except loss of thymine, from the cleavage of $\mathrm{N}$-glycosidic bonds were also present. In general, complete sequence coverage was achieved in all charge states. For the two LNA-DNA chimeras, however, dramatic differences in the relative contributions of the competing dissociation channels were observed among different precursor ion charge states. At lower charge states, sequence information limited to the a-Base $/ \mathrm{w}$-fragment ions from cleavage of the $3^{\prime} \mathrm{C}-\mathrm{O}$ bond of DNA nucleotides, except thymidine (dT), was acquired from CID of both the LNA gapmer and mixmer ions. On the other hand, extensive fragmentation from various dissociation channels was observed from post-ion/ion ion trap CID of the higher charge state ions of both LNA-DNA chimeras. This report demonstrates that tandem mass spectrometry is effective in the sequence characterization of LNA oligonucleotides and LNA-DNA chimeric therapeutics. (J Am Soc Mass Spectrom 2010, 21, 144-153) (C) 2010 American Society for Mass Spectrometry

S mall non-coding RNAs, such as small interfering RNAs (siRNAs), microRNAs (miRNAs) and piwi-interacting RNAs (piRNAs), are involved in gene regulation in eukaryotic cells. They are the recognition units of an enzyme/RNA complex (RNAinduced silencing complexes, RISCs) that lead to post-transcriptional RNA silencing. Despite their similarity in sizes (usually 20 30 nucleotides), the functions and mechanisms are distinctive [1,2]. Efforts have been devoted to the identification of their target genes and the cellular functions involved. Several small noncoding RNAs have been correlated to human diseases. For example, some miRNAs are involved in the regulation of oncogenes or tumor suppressor genes [3, 4]. A miRNA, miR-133b, has been identified as a regulator of the maturation and function of midbrain dopaminergic neurons involved in Parkinson's disease [5]. New classes of small noncoding RNAs continue to be discovered and their functions characterized [6-10]. These disease-related small RNAs could be potential therapeutic targets. Strategically, the functions of certain small RNAs can either be enhanced by introducing more copies of the small RNAs or be neutralized by introducing their antagonists into the cells using antisense techniques. To utilize small RNAs for these therapeutic purposes, major efforts have been directed

Address reprint requests to Dr. S. A. McLuckey, Department of Chemistry, Purdue University, 1393 Brown Laboratories, West Lafayette, IN 479071393, USA. E-mail: mcluckey@purdue.edu toward developing chemically-modified oligonucleotide analogs that can increase the binding specificity and cellular stability of small RNAs; at the same time, cytotoxicity and cellular delivery are also major concerns for successful oligonucleotide-based therapeutics. A variety of nucleotide analogs has been developed and the effectiveness of the various types as building blocks of therapeutic small RNAs has been evaluated [1, 11-13].

The locked nucleic acid (LNA) is one of the most promising nucleic acid analogs. The LNA nucleotides are RNA analogs that contain a methylene linkage between the $2^{\prime}$ oxygen and the $4^{\prime}$ carbon of the ribose ring. The furanose ring of LNA is locked into an RNA-like C3'-endo conformation. LNA has a very high affinity and specificity to its complementary DNA and RNA. Also, its stability in biological fluids is much higher due to its increase in nuclease resistance [14, 15]. The LNA-modified oligonucleotides have been used in several studies for various diagnostic and therapeutic applications such as single nucleotide polymorphism analysis [16], transcription factor decoys [17], triple helix formation and alteration of intron splicing [18], molecular beacons [19], and direct detection of abortive RNA transcripts in vivo [20]. LNA has also been employed to improve the stability and functionality of siRNAs and RNA aptamers [21, 22]. Stable inhibition of miRNA functions in nonhuman primates by unconjugated LNA-anti-miR oligonucleotides has also been reported [23]. Currently, several LNA-modified oligo- 
nucleotide drugs are in clinical trials. Two potentially effective therapeutic strategies have been reported using LNA-containing oligonucleotides. One of them, called LNA mixmer, has the LNA monomers incorporated into random positions of an oligonucleotide sequence. The mixmers act as antagonists (antisense oligonucleotides) to block the function of a specific RNA in a stoichiometric manner without the involvement of RNaseH. The other class of LNA-modified oligonucleotide, called LNA gapmer, has a DNA sequence flanked by two short stretches of LNA on both termini. The design of the LNA gapmer sequence allows the RNaseH function to degrade target RNAs [23-26]. These two designs for effective therapeutic LNA-DNA chimeras hold significant biomedical value in that either the decrease or the increase of small noncoding RNA functions can be achieved.

To use them for therapeutic and diagnostic purposes, the structural characterization of the synthetic oligonucleotides and/or their metabolites is required. However, conventional methods are usually not effective for the structure characterization of highly modified oligonucleotides. On the other hand, mass spectrometrybased methods are rapid and sensitive alternatives. Mass spectrometry-based analysis of therapeutic oligonucleotides has been reported in several studies. The identities of the oligonucleotide-drug and different metabolites can be confirmed by the mass measurements $[27,28]$. Farand and coworkers have demonstrated that sequence confirmation and de novo sequencing of highly modified oligonucleotides can be achieved via mass spectrometry of chemically degraded oligonucleotides and tandem mass spectrometry analysis of the short fragments $[29,30]$. However, this method requires additional sample preparation steps and its efficacy on LNA-modified oligonucleotides has not been demonstrated. In comparison to other analytical methods, tandem mass spectrometry of intact oligonucleotides is promising for its ability to effectively characterize molecules of diverse structures without prior chemical or enzymatic degradation. However, a better understanding of the gas-phase dissociation behavior of the modified oligonucleotides is a prerequisite. To the best of our knowledge, few studies have been reported on tandem mass spectrometry analysis of short modified oligonucleotides [31-33], and no tandem mass spectrometry-based methods to sequence either the LNA or LNA-containing oligonucleotides have been reported. Previously, tandem mass spectrometry analysis of single strand and duplex siRNAs has been investigated and full sequence coverage was obtained. However, the modification is limited to the $3^{\prime}$-terminus DNA overhang, and the overall molecules are composed of the RNA backbone [34]. Considering its unique structure, it is of interest to study the unimolecular dissociation of LNA in comparison to DNA and RNA. In this study, gas-phase dissociation of model LNA oligomers and two chimeric LNA-DNA oligonucleotides, the LNA gapmer and mixmer, have been investigated as a func- tion of precursor ion charge states using ion trap collision-induced dissociation (CID).

\section{Materials and Methods}

Methanol, isopropanol, and glacial acetic acid were purchased from Mallinckrodt (Phillipsburg, NJ, USA). Ammonium acetate and ethanol were obtained from Sigma-Aldrich (St. Louis, MO, USA). All LNA oligonucleotides, 5 mer $\left(\mathrm{GC}^{\mathrm{m}} \mathrm{AGT}\right), 8$ mer $\left(\mathrm{ATC}^{\mathrm{m}} \mathrm{GATC}^{\mathrm{m}} \mathrm{G}\right)$, mixmer $\left(5^{\prime}-\mathrm{C}^{\mathrm{m}} \mathrm{cAttGTcaC} \mathrm{aC}^{\mathrm{m}} \mathrm{tC}^{\mathrm{m}} \mathrm{C}^{\mathrm{m}}-3^{\prime}\right)$, and gapmer (5'-GGGcttcttccttattgATGG-3'), were custom synthesized by Integrated DNA Technologies (Coralville, IA, USA). (All LNA nucleotides are labeled in upper case; DNA residues are labeled in lower case). The cytosine residues in all LNA oligonucleotides were replaced by methyl cytosine $\left(\mathrm{C}^{\mathrm{m}}\right)$. The sequence of the mixmer was chosen based on the work of Elmen et al. [23]. The sequence of gapmer was chosen based on the work of Rapozzi et al. [24]. The LNA samples were used without further purification. LNA solutions for negative nano-electrospray were prepared by diluting the aqueous stock solutions to ca. $50 \mu \mathrm{M}$ in 20:80 (vol:vol) isopropanol:water with the addition of $25 \mathrm{mM}$ piperidine and $25 \mathrm{mM}$ imidazole [35].

All experiments were performed using a prototype version of a QqTOF tandem mass spectrometer modified to allow for ion trap CID and ion/ion reaction studies [36]. A home-built pulsed dual nano-electrospray (ESI) source was coupled directly to the nanospray interface to produce ions of both polarities [37]. Detailed experimental procedures have been reported previously [34]. In brief, a typical scan function consisted of LNA ion injection, isolation of the charge states of interest by Q1 in RF/DC mode, ion trap collision-induced dissociation (CID) in Q2, and then mass analysis by TOF. To remove charge state ambiguity of the CID product spectra from dissociation of the higher charge state ions, proton transfer ion/ion reactions were employed to reduce the fragment ion charge states. To generate the proton transfer reagent cations, benzoquinoline was placed inside of the curtain plate. The benzoquinoline vapor is subsequently ionized by the nano-ESI generated positively-charged droplet. To conduct pseudo-MS ${ }^{3}$ experiments, the LNA anions were fragmented in the atmosphere/vacuum interface by increasing the potential difference between the nozzle and skimmer. The fragment ions of interest were isolated in Q1 and then subjected to ion trap CID.

\section{Results and Discussion}

\section{Ion Trap Collision-Induced Dissociation of Model LNA Oligomers}

LNA is an oligonucleotide analog with exceptional hybridization affinity toward its complementary DNA and RNA. The unique structure allows for characteristics suitable for use in the oligonucleotide-based drug 
development. While their chemical and physical properties in the solution phase have been well characterized [14, 15, 38], the gas-phase characteristics, such as stability and unimolecular dissociation chemistry, have not been investigated. In this study, an LNA 5 mer $\left(\mathrm{GC}^{\mathrm{m}} \mathrm{AGT}\right)$ and an 8 mer $\left(\mathrm{ATC}^{\mathrm{m}} \mathrm{GATC}^{\mathrm{m}} \mathrm{G}\right)$, containing all four LNA monomers, i.e., $A, T, G$, and $C^{m}$, were used as model systems to study the gas-phase dissociation of LNA upon collisional activation. The dissociation phenomena of the LNA oligomers were investigated as a function of charge state using ion trap CID.

As shown in Scheme $\mathbf{1}$ in the supplementary data, which can be found in the electronic version of this article, the nomenclature often used for DNA and RNA dissociation [39] is well-suited for the dissociation of LNA. For DNA, base losses and the generation of the $\mathrm{a}-\mathrm{B} / \mathrm{w}$-ions are the predominant dissociation channels under collisional activation conditions. For RNA, base losses and $5^{\prime} \mathrm{P}-\mathrm{O}$ bond cleavage to yield $\mathrm{c} / \mathrm{y}$-ions are the lowest energy dissociation channels, and a-Base/wions, which result from sequential cleavage from the base loss products, can also be observed when higher internal energy deposition is achieved. For the gasphase dissociation of LNA, four possible cleavage sites on the phosphodiester backbone can lead to the generation of four types of characteristic ion pairs, i.e., $\mathrm{a} / \mathrm{w}$-ions, $\mathrm{b} / \mathrm{x}$-ions, $\mathrm{c} / \mathrm{y}$-ions, and $\mathrm{d} / \mathrm{z}$-ions. The cleavage of $\mathrm{N}$-glycosidic bonds leads to nucleobase losses, and the subsequent cleavage of the $3^{\prime} \mathrm{C}-\mathrm{O}$ bond from the base loss ions gives rise to the $\mathrm{a}-\mathrm{B} / \mathrm{w}$-ions. The masses of these possible fragment ions were calculated manually and were then matched against the fragment ions from the ion trap CID fragment ion spectra.

Figure 1 shows the ion trap tandem mass spectra of the doubly deprotonated LNA oligonucleotides (GC ${ }^{\mathrm{m}} \mathrm{AGT}$ and $\left.\mathrm{ATC}^{\mathrm{m}} \mathrm{GATC}^{\mathrm{m}} \mathrm{G}\right)$. In both cases, a large majority of the product ions could be assigned to fragment ions expected from backbone cleavages as well as base loss and subsequent backbone cleavage. Collisional activation of the doubly deprotonated LNA led to the cleavage of all backbone bonds, generating $\mathrm{a} / \mathrm{w}^{-}, \mathrm{b} / \mathrm{x}-, \mathrm{c} / \mathrm{y}^{-}$, and $\mathrm{d} / \mathrm{z}$-ions. No preferential backbone bond cleavage was observed consistently for all linkages. Neutral base losses, except the loss of thymine, were also present. The consecutive loss of neutral $\mathrm{C}^{\mathrm{m}}$ and water was also observed in the CID spectrum. Unlike DNA, however, base loss was not observed to be the dominant pathway as backbone cleavages appeared to be highly competitive with base loss. In comparison to the dissociation of DNA and RNA, only minimal abundances of a-Base ions were observed, presumably due to the relatively stable gas-phase structure of the base loss ion from LNA. The mechanism for the formation of the a-Base type ions has been proposed for DNA. Following the neutral base losses, the abstraction of the hydrogen from $\mathrm{C} 4$ of the ribose ring leads to the

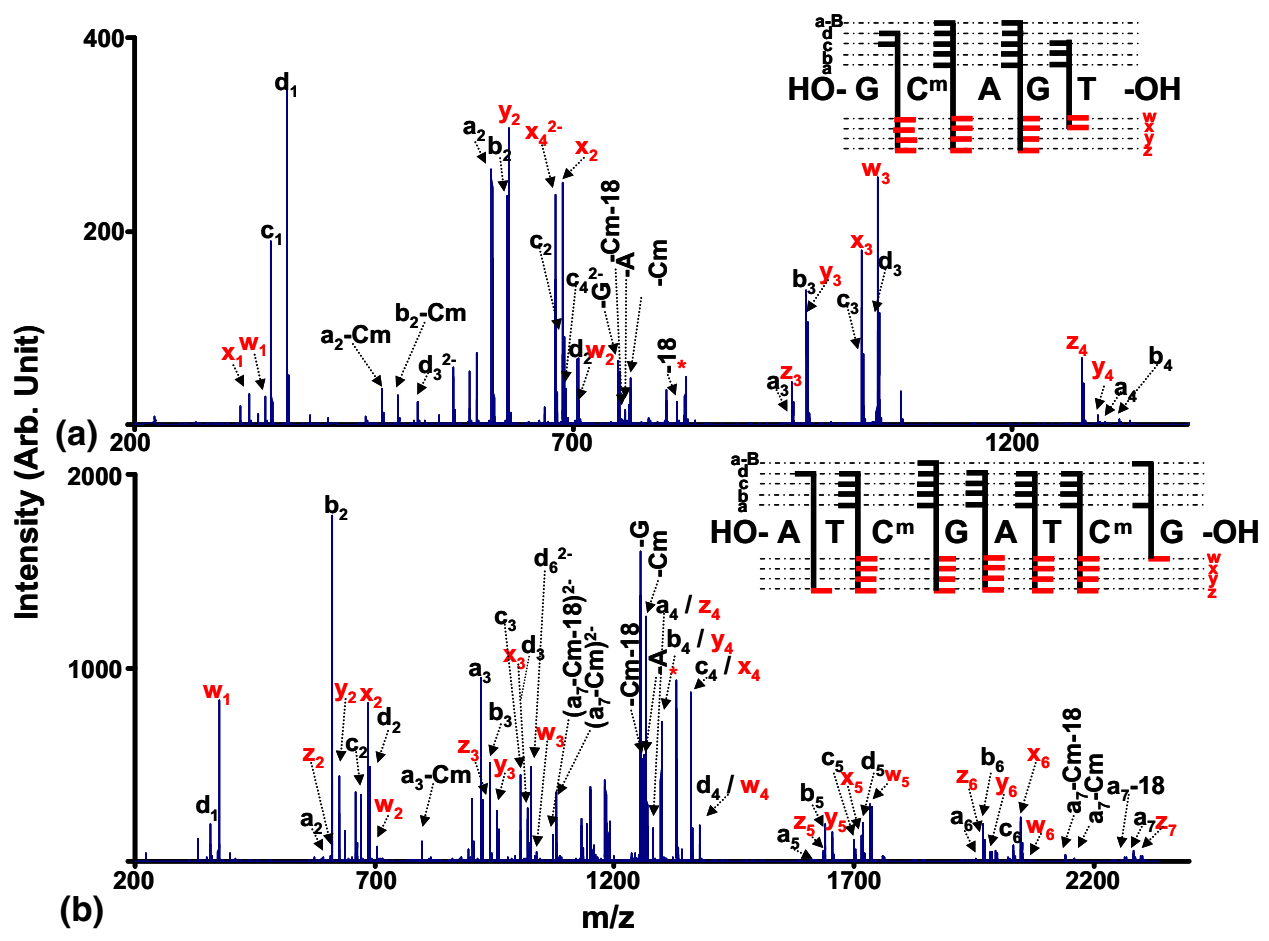

Figure 1. Ion trap tandem mass spectra of the doubly deprotonated ions of the LNA model oligonucleotides: (a) product ion spectrum of $[\mathrm{M}-2 \mathrm{H}]^{2-}$ of the LNA 5 mer, GC ${ }^{\mathrm{m}} \mathrm{AGT}$, at an excitation amplitude of $500 \mathrm{mV}(105 \mathrm{kHz})$; (b) product ion spectrum of $[\mathrm{M}-2 \mathrm{H}]^{2-}$ of the LNA 8 mer, ATC ${ }^{\mathrm{m}} \mathrm{GATC}{ }^{\mathrm{m}} \mathrm{G}$, at an excitation amplitude of $1000 \mathrm{mV}(65.5 \mathrm{kHz})$. The asterisk denotes the [M $2 \mathrm{H}]^{2-}$ precursor ions. The inset provides a summary of backbone cleavages resulting from ion trap CID of the LNA oligonucleotides. 
subsequent $3^{\prime} \mathrm{C}-\mathrm{O}$ bond cleavage and the formation of a furan ring [40]. For LNA, the methylene bridging the $\mathrm{O} 2$ ' $-\mathrm{C}^{\prime}$ ' of the ribose prohibits the formation of a furan ring after base loss, and therefore inhibits this dissociation channel. The $\mathrm{c} / \mathrm{y}$-ion series, which is the lowest energy dissociation channel for RNA, is observed for the dissociation of LNA, but it is not the most favorable dissociation channel. This result is not surprising since the presence of the 2' hydroxyl group on the RNA sugar ring facilitates cleavage of the $5^{\prime} \mathrm{P}-\mathrm{O}$ bond on RNA $[32,41,42]$. Hence, the bridging methylene group modification to the sugar of the LNA removes major factors that give rise to favored backbone cleavages in both RNA and DNA. As a result, there appears to be no strongly favored backbone cleavage channel in the LNA such that cleavages from a variety of backbone bonds are observed.

The dearth of a-B ions was further investigated via pseudo-MS ${ }^{3}$ experiments. The nano-ESI generated LNA anions were subjected to fragmentation in the atmosphere/vacuum interface region by nozzle-skimmer dissociation. To investigate the dissociation behavior of the base loss ions, the $[\mathrm{M}-2 \mathrm{H}-\mathrm{G}]^{2-}$ ion of the LNA 8 mer was isolated and then subjected to ion trap CID (Figure 2). As shown in Figure 2, although $\mathrm{a}_{4}-\mathrm{G}$ and $\mathrm{w}_{4}$-ions, which are generated from the cleavage of the $3^{\prime}$ $\mathrm{C}-\mathrm{O}$ bond of $\mathrm{G}$, were observed from the pseudo-MS ${ }^{3}$ spectrum, the two channels were not dominant. Instead, three major dissociation channels were observed from ion trap CID of $(\mathrm{M}-2 \mathrm{H}-\mathrm{G})^{2-}$. Consecutive water losses $\left(-\mathrm{H}_{2} \mathrm{O}\right.$ and $\left.-2 \mathrm{H}_{2} \mathrm{O}\right)$ were the predominant dissociation channels. Low abundant ions from the subsequent loss of neutral bases $(-\mathrm{Cm}>-(\mathrm{Cm}+18)>-\mathrm{A} 0>-\mathrm{G} 0)$ were also observed. The secondary backbone bond cleavages from the $(\mathrm{M}-2 \mathrm{H}-\mathrm{G})^{2-}$ ions also generated fragment ions observed in the MS2 spectra $(a / w, b / x$, $c / y$ and $d / z$ ) and extensive fragment $-G$ ions, such as z3-G, x5-G, a4-G and d6-G. This pseudo-MS ${ }^{3}$ experiment supports the conclusion that the modification associated with LNA inhibits the subsequent cleavage of the 3' $\mathrm{C}-\mathrm{O}$ bond of the sugar that loses the base, which is a facile process in both DNA and RNA anions.
The charge state effect on the gas-phase dissociation of LNA anions was also investigated. The multiply deprotonated LNA anions of various charge states $\left([\mathrm{M}-\mathrm{H}]^{-}-[\mathrm{M}-4 \mathrm{H}]^{4-}\right.$ of the 5 mer and $[\mathrm{M}-\mathrm{H}]^{-}-$ $[\mathrm{M}-5 \mathrm{H}]^{5-}$ of the 8 mer) were each isolated and subjected to ion trap collisional activation under various excitation amplitudes (for a summary of observed dissociation channels, see Figure S-1 in the supplementary information). Variations in the relative abundances of different fragment ions were observed for the two oligonucleotides as a function of charge state. For the LNA 8 mer, only the $d 1 / z 7$-ions were observed for the $5^{\prime}$ terminal residue and only the a7/w1-ions were observed for the $3^{\prime}$ terminal residue throughout most of the charge states investigated. For the LNA 5 mer, however, a wider range of fragment ion types was observed for both the $5^{\prime}$ and $3^{\prime}$ terminal residues. Also, a preference for $5^{\prime} \mathrm{O}-\mathrm{C}$ bond cleavages and the generation of the $\mathrm{d} / \mathrm{z}$-ions at higher charge states was observed for the LNA 8 mer; however, this preference was not observed for the LNA 5 mer. Qualitatively, however, very similar dissociation phenomena were obtained throughout different charge states. Both charged and neutral base losses were observed together with fragment ions from almost all possible backbone bond cleavages at high excitation amplitudes. Full sequence coverage can be obtained from CID of the LNA 5 and 8 mer.

\section{Ion Trap Collision-Induced Dissociation of Functional LNA-DNA Chimeras}

To evaluate the utility of tandem mass spectrometry in the structural characterization of modified LNA-DNA oligonucleotides, the gas-phase dissociation of two model LNA-DNA chimeras in a linear ion trap mass spectrometer was investigated, and the charge state effects were compared. Selection of the sequence of the LNA gapmer (5'-GGGcttcttccttattgATGG-3') was inspired by the work of Rapozzi et al. [24]. The LNA gapmer can reduce the transcript level of an oncogene leading to chronic myeloid leukemia. The sequence of

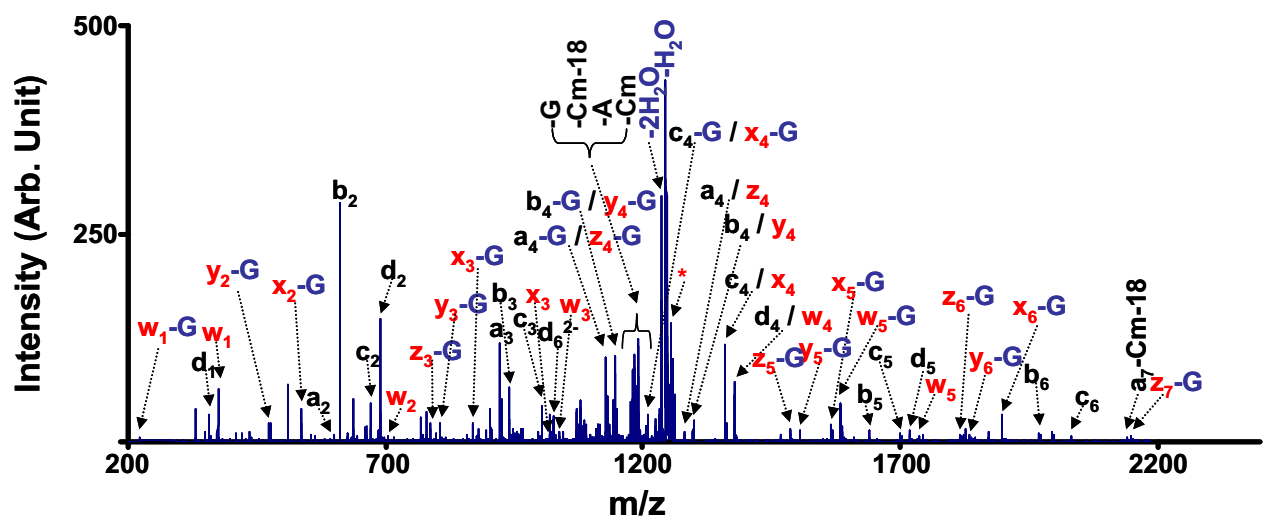

Figure 2. Ion trap tandem mass spectrum of the $(\mathrm{M}-2 \mathrm{H}-\mathrm{G})^{2-}$ of the LNA 8 mer, $\mathrm{ATC}^{\mathrm{m}} \mathrm{GATC}^{\mathrm{m}} \mathrm{G}$, at an excitation amplitude of $350 \mathrm{mV}(69 \mathrm{kHz})$. 
the LNA mixmer $\left(5^{\prime}-C^{m}\right.$ AttGTcaC $\left.{ }^{m} a C^{m} C^{m} C^{m}-3^{\prime}\right)$ was inspired by the work of Elmer et al. [23]. The LNA mixmer can act effectively as an anti-miRNA to the liver-specific mir-122. Although the backbone of the LNA mixmer was either completely or partially modified by phosphorothioate in the original work, the oligonucleotides used in this study are composed of only LNA and DNA monomers. The LNA mixmer was ionized via nano-ESI in the negative ion mode. Multiply deprotonated LNA mixmer anions were isolated and then subjected to ion trap CID. Figure 3 shows the ion trap CID product ion spectrum of the LNA mixmer $[\mathrm{M}-3 \mathrm{H}]^{3-}$ ion. Cleavages of the DNA 3' $\mathrm{C}-\mathrm{O}$ bonds following base losses were the dominant dissociation channel generating $\mathrm{a}-\mathrm{B}$ - and $\mathrm{w}$-ions for the LNA mixmer. Two ions with the mass-to-charge ratios corresponding to the $\mathrm{y}_{3^{-}}$and $\mathrm{y}_{5}$-ions were also observed. However, in general, little evidence for cleavages $3^{\prime}$ to LNA monomer or DNA thymidine was observed.

As has been reported previously, the dissociation of oligonucleotide anions can be highly sensitive to precursor ion charge state [43-45]. To investigate the dissociation behavior of the LNA mixmer anions of higher charge states, the $[\mathrm{M}-7 \mathrm{H}]^{7-}$ ions were isolated and subjected to ion trap CID. The interpretation of the spectrum was facilitated by applying ion/ion proton transfer reactions, using benzoquinoline cations as the charge reducing reagent ions [34], to reduce the product ion charge states to mostly 2- and 1-. As shown in the post-ion/ion ion trap CID product ion spectrum of the $[\mathrm{M}-7 \mathrm{H}]^{7-}$ LNA mixmer (Figure 4), significantly greater structural information resulted from fragmentation of the higher charge state precursor ion. In addition to the base loss ions, the $\mathrm{a}-\mathrm{B} / \mathrm{w}$-ions from the cleavage of the 3' $\mathrm{C}-\mathrm{O}$ bond following nucleobase losses from the DNA residues were still the most preferred dissociation channels, as seen from the relatively high signal abundances. Relatively high abundances of the $\mathrm{a}_{4} / \mathrm{w}_{11^{-}}$ and $\mathrm{a}_{5} / \mathrm{w}_{10}$-ions from the cleavages of the $3^{\prime} \mathrm{C}-\mathrm{O}$ bonds without the prior losses of thymine were also observed. Lower but still significant abundances of fragment ions from other dissociation channels were also present in the post-ion/ion product ion spectrum. Some of these ions were from the DNA backbone cleavages, while others were from the LNA backbone cleavages. It is apparent that the appearance of either the LNA monomer or DNA thymidine in the oligonucleotide sequences can lead to limited backbone cleavages when precursor anions of low charge are subjected to collisional activation. Fortunately, dissociation of precursor ions of higher charge states allows access to dissociation channels that provide more comprehensive primary sequence information.

Figure 5 shows the ion trap CID product ion spectrum of the $[\mathrm{M}-4 \mathrm{H}]^{4-}$ ion of the LNA gapmer (5'-GGGcttcttccttattgATGG-3'). Similar to the dissociation of the lower charge state of the LNA mixmer anions, no backbone bond cleavages from either the LNA monomers or the DNA thymidines were observed. The a-B/w-ions corresponding to the subsequent $3^{\prime} \mathrm{C}-\mathrm{O}$ bond cleavage from the DNA base loss ions, $\mathrm{M}-\mathrm{dC}, \mathrm{M}-\mathrm{dA}$, and $\mathrm{M}-\mathrm{dG}$, were the dominant sequence ions. In addition, a highly abundant peak at $m / z 785$, corresponding to the internal fragmentation from the cleavage of one glycosidic bond and two $3^{\prime}$ $\mathrm{C}-\mathrm{O}$ bonds was also observed. This ion, corresponding to the mass of two thymidines, $5^{\prime}$ and $3^{\prime}$ phosphate groups and a furan ring, reflects the high number of adjacent thymidines in the gapmer sequence. It can be either the $a-B$ ion from one of the $w$ ions of the precursor ion or the $\mathrm{w}$ ion from one of the a-B ions of the precursor ion. There are other unidentified secondary fragment ions of lower abundance as well. Due to the high content of LNA monomer and DNA thymidine

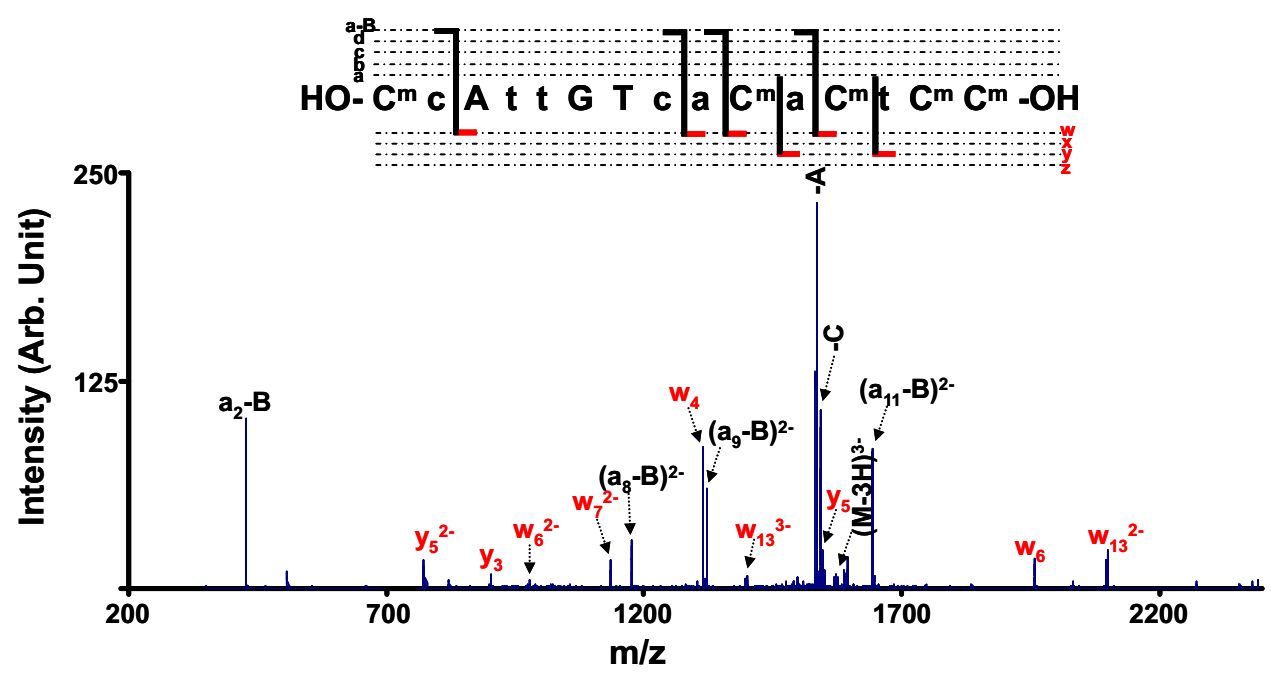

Figure 3. Ion trap tandem mass spectrum of $[\mathrm{M}-3 \mathrm{H}]^{3-}$ of the LNA mixmer at an excitation amplitude of $600 \mathrm{mV}(82.5 \mathrm{kHz})$. The inset provides a summary of backbone cleavages resulting from ion trap CID of the $[\mathrm{M}-3 \mathrm{H}]^{3-}$. 


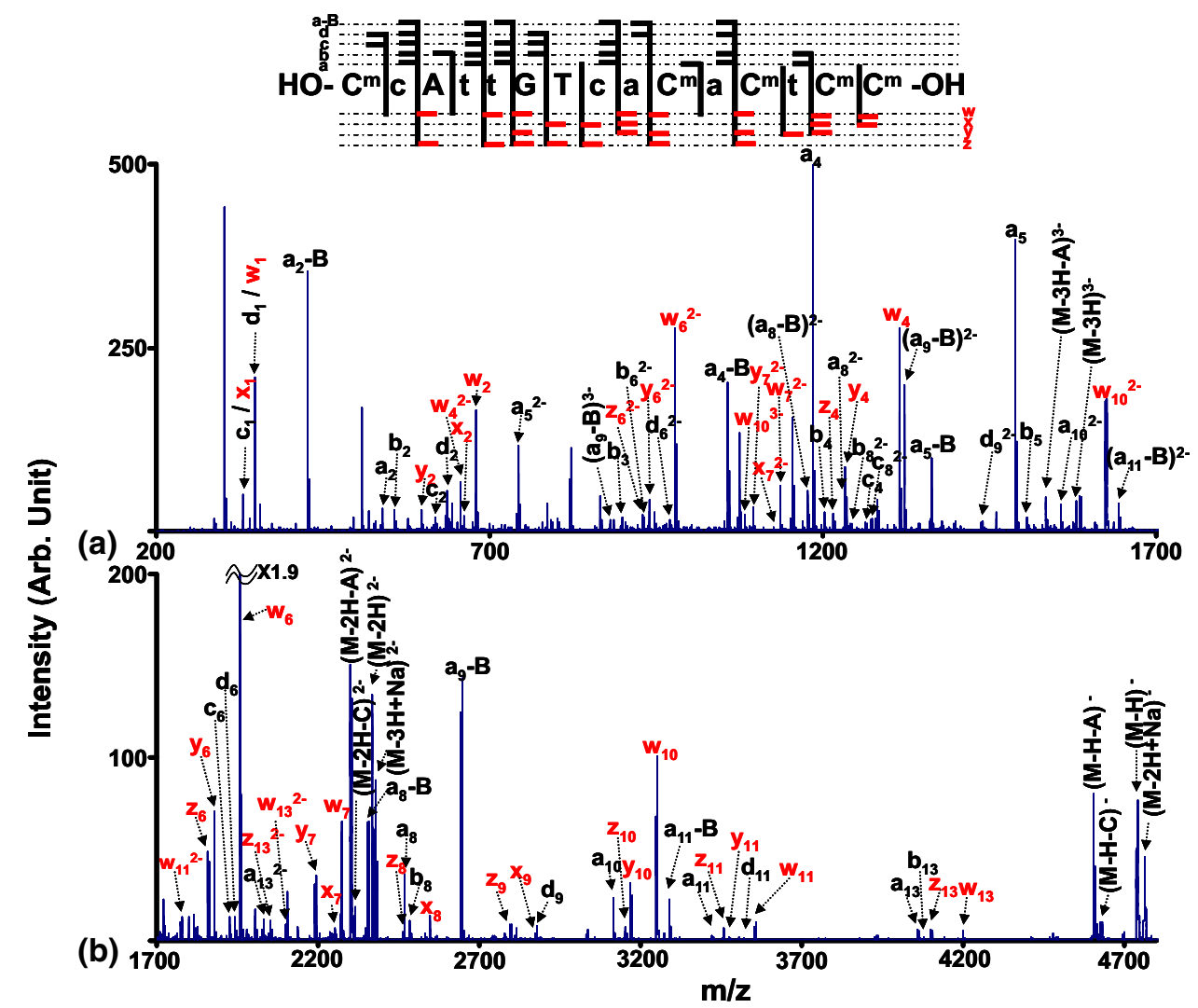

Figure 4. Post-ion/ion ion trap CID spectrum of LNA mixmer 7-. (99.93 kHz, $480 \mathrm{mV})$; (a) and (b) correspond to mass range $\mathrm{m} / \mathrm{z} 200 \sim 1700$ and $1700 \sim 4700$, respectively. The inset provides a summary of backbone cleavages resulting from post-ion/ion ion trap CID of the $[\mathrm{M}-7 \mathrm{H}]^{7-}$.

in the sequence, the sequence coverage for this relatively low precursor ion charge state is limited.

The gas-phase dissociation behavior of the LNA gapmer at higher charge state was further investigated. Figure 6 shows the post-ion/ion ion trap CID product ion spec- trum of the $[\mathrm{M}-9 \mathrm{H}]^{9-}$ LNA gapmer. In contrast to the dissociation of $[\mathrm{M}-9 \mathrm{H}]^{4-}$ (Figure 5), extensive backbone bond fragmentation was observed for the LNA gapmer. In addition to the a-B/w-ions, extensive cleavage of the $5^{\prime}$ $\mathrm{P}-\mathrm{O}$ bond in the DNA region of the LNA-DNA gapmer

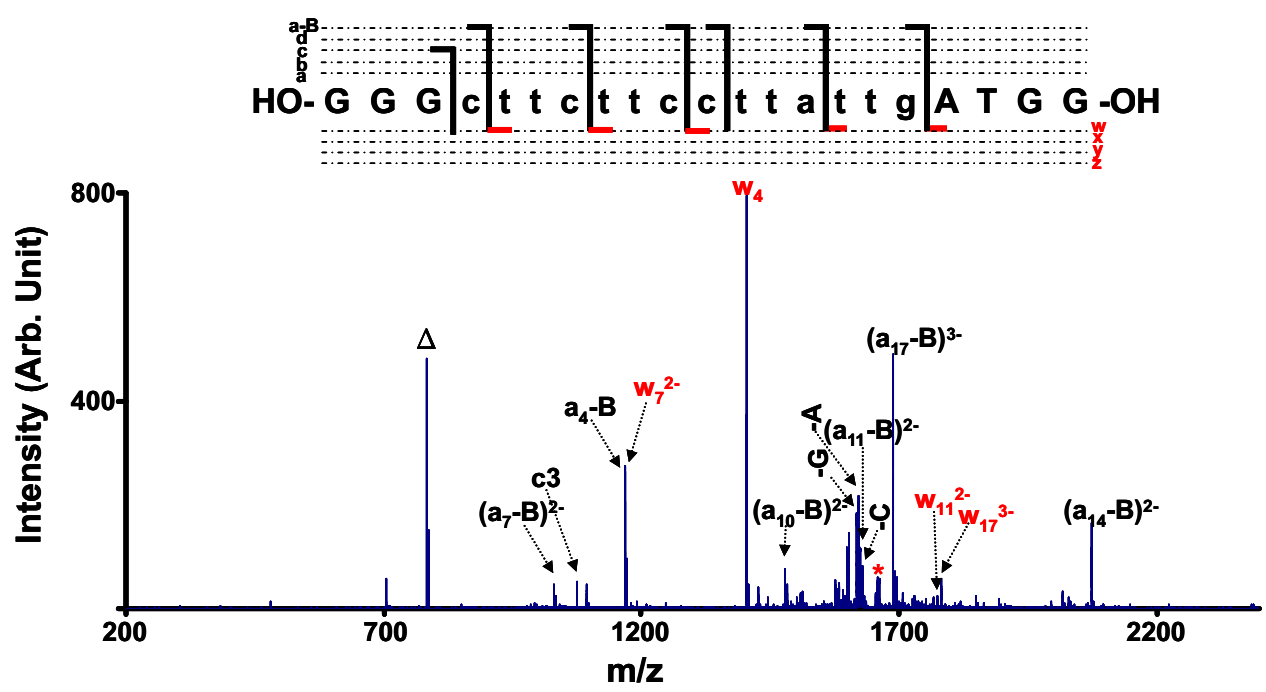

Figure 5. Ion trap tandem mass spectra of $(\mathrm{M}-4 \mathrm{H})^{4-}$ of the LNA gapmer at an excitation amplitude of $700 \mathrm{mV}(79 \mathrm{kHz}) . \Delta$ : internal fragmentation. The inset provides a summary of backbone cleavages resulting from ion trap CID of the $[\mathrm{M}-4 \mathrm{H}]^{4-}$. 


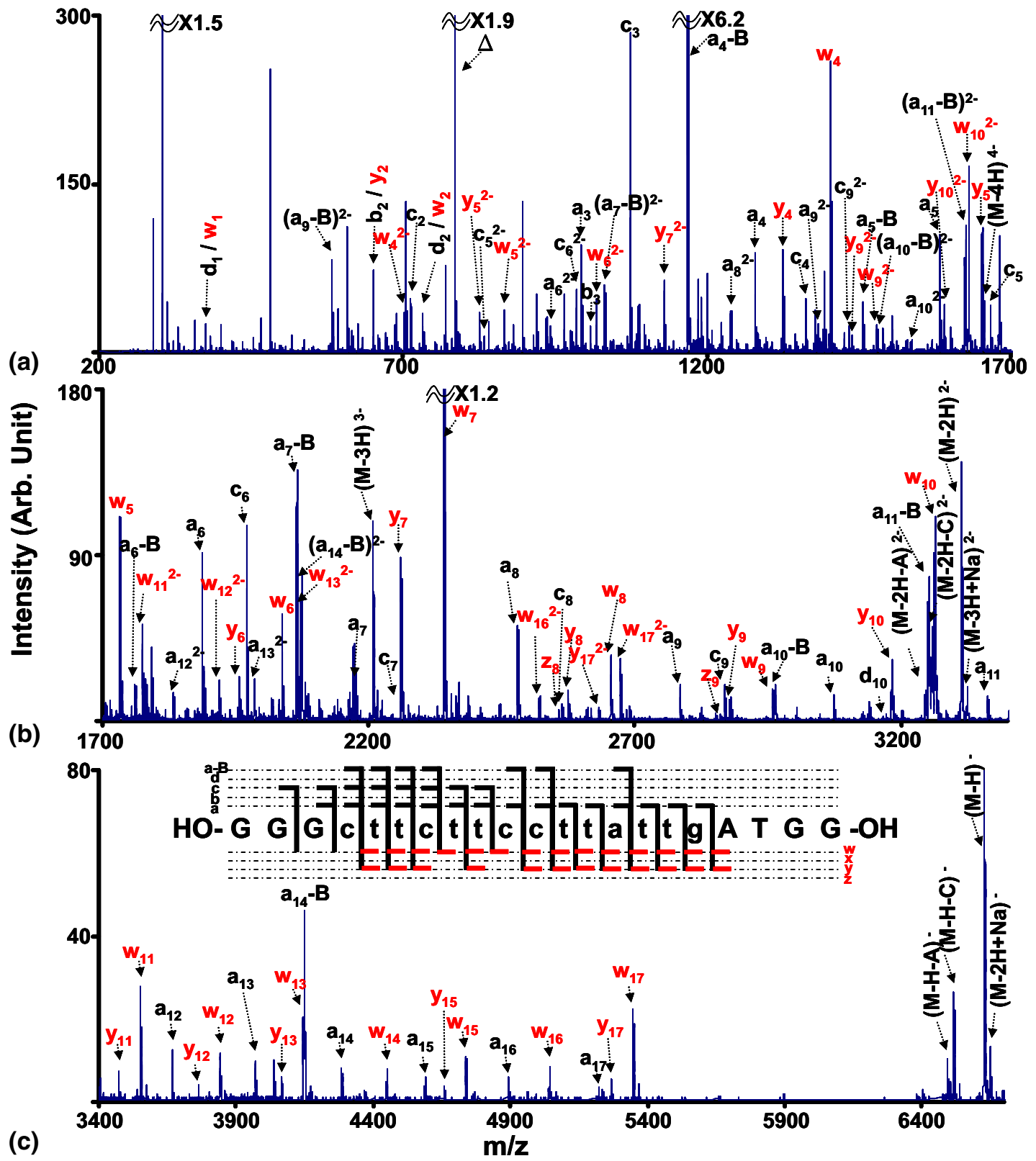

Figure 6. Post-ion/ion ion trap CID spectrum of LNA gapmer 9- $(179 \mathrm{kHz}, 700 \mathrm{mV})$; (a), (b), and (c) correspond to mass range $m / z 200 \sim 1700,1700 \sim 3400$, and 3400 6700, respectively. $\Delta$ : internal fragmentation at $m / z 785$. The inset in (c) provides a summary of backbone cleavages resulting from post-ion/ion ion trap CID of the $[\mathrm{M}-9 \mathrm{H}]^{9}$.

generated series of $\mathrm{c}$ ions and y ions. Abundant fragment ions corresponding to cleavage of the $3^{\prime} \mathrm{C}-\mathrm{O}$ bond without prior loss of thymidine were also present. Extensive secondary fragmentation was also observed leading to the background unassigned peaks in the spectrum. However, the LNA-containing termini remained largely silent to dissociation. In general, ion trap CID on precursor ions of higher charge states gave higher sequence coverage than lower charge states.

Based on the observations made with anions of the model LNA oligomers and the mixmer and gapmer, there appears to be three major factors that influence the extent of sequence information that can be generated by ion trap CID of the deprotonated species. It is obvious, for example, that monomer identities in the oligonucleotide sequence (i.e., the presence of DNA thymidine and LNA monomers) are major factors for the relatively low sequence information acquired from ion trap CID of the LNA mixmer and LNA gapmer, particularly at low activation amplitudes. A second factor is precursor ion charge state, with higher charge states generally providing richer structural information. The third factor is activation conditions with higher resonance excitation amplitudes providing more extensive backbone cleavage as well as more extensive sequential dissociation. 
The backbone of an oligonucleotide on the $3^{\prime}$ side of a sugar with the LNA modification is stabilized with respect to fragmentation, relative to RNA and DNA residues. In the LNA modified species, the 2 ' hydroxyl group is converted to an ester, which precludes the facile mechanism in RNA that yields complementary c/y-ions, and the 4' hydrogen normally present in unmodified sugars, which is necessary for the facile $3^{\prime}$ $\mathrm{C}-\mathrm{O}$ bond cleavage from base loss ions to yield a-Base/ $\mathrm{w}$-ions is replaced by a methylene group in the LNA sugar. As a result of these differences, there are no particularly low-energy backbone dissociation pathways for the LNA residues so that cleavages at all backbone bonds are more competitive with one another. However, when there are mixed residue types, those with the LNA modification do not compete with unmodified residues. In this work, the unmodified residues were DNA nucleotides. The LNA backbone bonds are generally more resistant to gas-phase dissociation than DNA. In addition, loss of nucleobase from LNA monomer lead to mostly consecutive water losses, base losses and low abundant secondary fragment ions. Similar observations would be expected for RNA nucleotides as the mechanism that gives rise to $\mathrm{c} / \mathrm{y}$-ions has been noted to be a lower energy process than that giving rise to a-B/w-ions [45].

The richer array of sequence informative ions generated from the more highly charged precursor ions might reflect a role for electrostatic repulsion in weakening backbone bonds in such a way as to make a wider variety of dissociation channels more competitive. As charge increases, one of the mechanisms for the formation of a-B/w-ions is also expected to be less important. At moderate to low charge states, for example, proton transfer from a neutral phosphodiester linkage to a nucleobase has been proposed to precede base loss [46-48]. This is consistent with the minimal loss of thymine, which has a significantly lower proton affinity than the other nucleobases, observed from the T-containing anions examined here. Loss of thymine as an anion, however, has been noted to be competitive to losses of other charged bases in oligonucleotide anions with most of the phosphodiester linkages being charged. In the case of the gapmer, the $[\mathrm{M}-9 \mathrm{H}]^{9-}$ precursor ion gave much more sequence information than the $[\mathrm{M}-4 \mathrm{H}]^{4-}$ ion but in neither case were most of the phosphodiester linkages (20 are present in the gapmer studied here) charged. The $[\mathrm{M}-9 \mathrm{H}]^{9-}$ was the most highly charged abundant ion in the electrospray mass spectrum of the gapmer. No concerted efforts were made to generate ions of higher charge state. However, if it were possible to generate ions of higher charge state, there is the possibility that some fragmentation from the LNA residues might be more competitive.

In practice, ion trap CID of the LNA-DNA chimeras of lower charge states provides simple and predictable sequence specific fragment ions, which is analogous to the restriction enzyme digestion of oligonucleotides. The dis- sociation pattern provides an additional measurement for the accurate synthesis of the oligonucleotide-based therapeutics in addition to their molecular masses. The preferred dissociation channels are dependent on the types of nucleotide monomer (i.e., the backbone bonds of $\mathrm{dA}$, $\mathrm{dG}$, and $\mathrm{dC}$ tend to dissociate more easily than those of $\mathrm{dT}$ and the LNA monomers) and more-or-less independent of their positions. Consequently, depending on the composition of the oligonucleotides, higher sequence coverage can be obtained when the major components are DNA (dA, dG, and $d C)$. Since the spectra are relatively simple, the oligonucleotide sequences can be confirmed without conducting the experiment in a high-performance mass spectrometer. On the other hand, ion trap CID of the higher charge state precursor ions usually gives rise to higher sequence coverage. However, multiply deprotonated fragment ions from various dissociation channels together with abundant secondary fragmentation may complicate the spectra, which is a major tradeoff. Therefore, mass spectrometers of higher performance may be needed. In this study, it has been demonstrated that the tandem mass spectrometry analysis is effective for the sequence characterization of intact functional LNA-DNA oligonucleotides.

\section{Conclusions}

In this study, the dissociation behavior of LNA anions under ion trap collisional activation conditions has been investigated. Unlike DNA and RNA anions, no preferential dissociation channels were observed for LNA anions. The majority of the fragment ions resulted from the losses of nucleobases and various backbone bond cleavages with no significant preference. On the other hand, sequence characterization of the LNA-DNA chimeras was more complicated under ion-trap CID conditions. The backbone bonds of the LNA subunits are much more stable than those of the DNA subunits at lower charge states due to the nature of the sugar modification. Therefore, the fragment ions were mostly generated from the preferred dissociation of DNA nucleobase losses and the subsequent $3^{\prime} \mathrm{C}-\mathrm{O}$ bond cleavages when both LNA and DNA monomers were in the sequence; while the backbone bond dissociation from the LNA units was minimal. However, at higher charge states and with higher activation amplitudes, more sequence informative cleavages were noted in general. Overall, the major factors observed here that affect the extent of sequence information include the identities of the residues, with LNA and DNA dT residues being most resistant to cleavage, precursor ion charge state, and activation amplitude.

The development of oligonucleotide-based therapeutics is a fast growing research field. While strategies have been devised to develop more stable and effective oligonucleotide drugs, which involve incorporating different types of modifications at different positions, the sequence composition of these types of oligonucleotides 
are more complex. However, conventional methods for oligonucleotide sequencing are ineffective in characterizing these modified molecules. To analyze these molecules using tandem mass spectrometry, a better understanding of the gas-phase stability of different modified nucleotide analogs is desirable. The present study demonstrates that tandem mass spectrometry using ion trap CID can be effective in the structural characterization of LNA-based therapeutic oligonucleotides and highlights the important role the sugar structure plays in determining preferred backbone dissociation channels.

\section{Acknowledgments}

The authors acknowledge support for this research by the National Science Foundation under CHE-0808380.

\section{Appendix A Supplementary Material}

Supplementary material associated with this article may be found in the online version at doi:10.1016/ j.jasms.2009.09.020.

\section{References}

1. Dorsett, Y.; Tuschl, T. SiRNAs: Applications in Functional Genomics and Potential as Therapeutics. Nat. Rev. Drug Discov. 2004, 3, 318-329.

2. Carthew, R. W.; Sontheimer, E. J. Origins and Mechanisms of miRNAs and siRNAs. Cell 2009, 136, 642-655.

3. Calin, G. A.; Croce, C. M. MicroRNA-Cancer Connection: The Beginning of a New Tale. Cancer Res. 2006, 66, 7390-7394.

4. Ventura, A.; Jacks, T. MicroRNAs and Cancer: Short RNAs Go a Long Way. Cell 2009, 136, 586-591.

5. Kim, J.; Inoue, K.; Ishii, J.; Vanti, W. B.; Voronov, S. V.; Murchison, E.; Hannon, G.; Abeliovich, A. A MicroRNA Feedback Circuit in Midbrain Dopamine Neurons. Science 2007, 317, 1220-1224

6. Mattick, J. S. Noncoding RNAs: The Architects of Eukaryotic Complexity. EMBO Rep. 2001, 2, 986-991.

7. Mattick, J. S. The Functional Genomics of Noncoding RNA. Science 2005, 309, 1527-1528.

8. Carninci, P.; Kasukawa, T.; Katayama, S.; Gough, J.; Frith, M. C.; Maeda, N.; Oyama, R.; Ravasi, T.; Lenhard, B.; Wells, C.; Kodzius, R.; Shimokawa, K.; Bajic, V. B.; Brenner, S. E.; Batalov, S.; Forrest, A. R. R.; Zavolan, M.; Davis, M. J.; Wilming, L. G.; Aidinis, V.; Allen, J. E.; Ambesi-Impiombato, X.; Apweiler, R.; Aturaliya, R. N.; Bailey, T. L.; Bansal, M.; Baxter, L.; Beisel, K. W.; Bersano, T.; Bono, H.; Chalk, A. M.; Chiu, K. P.; Choudhary, V.; Christoffels, A.; Clutterbuck, D. R.; Crowe, M. L.; Dalla, E.; Dalrymple, B. P.; de Bono, B.; Della Gatta, G.; di Bernardo, D.; Down, T.; Engstrom, P.; Fagiolini, M.; Faulkner, G.; Fletcher, C. F.; Fukushima, T.; Furuno, M.; Futaki, S.; Gariboldi, M.; Georgii-Hemming, P.; Gingeras, T. R.; Gojobori, T.; Green, R. E.; Gustincich, S.; Harbers, M.; Hayashi, Y.; Hensch, T. K.; Hirokawa, N.; Hill, D.; Huminiecki, L.; Iacono, M.; Ikeo, K.; Iwama, A.; Ishikawa, T.; Jakt, M.; Kanapin, A.; Katoh, M.; Kawasawa, Y.; Kelso, J.; Kitamura, H.; Kitano, H.; Kollias, G.; Krishnan, S. P. T.; Kruger, A.; Kummerfeld, S. K.; Kurochkin, I. V.; Lareau, L. F.; Lazarevic, D.; Lipovich, L.; Liu, J.; Liuni, S.; McWilliam, S.; Babu, M. M.; Madera, M.; Marchionni, L.; Matsuda, H.; Matsuzawa, S.; Miki, H.; Mignone, F.; Miyake, S.; Morris, K.; Mottagui-Tabar, S.; Mulder, N.; Nakano, N.; Nakauchi, H.; Ng, P.; Nilsson, R.; Nishiguchi, S.; Nishikawa, S.; Nori, F.; Ohara, O.; Okazaki, Y.; Orlando, V.; Pang, K. C.; Pavan, W. I.; Pavesi, G.; Pesole, G.; Petrovsky, N.; Piazza, S.; Reed, J.; Reid, J. F.; Ring, B. Z.; Ringwald, M.; Rost, B.; Ruan, Y.; Salzberg, S. L.; Sandelin, A.; Schneider, C.; Schonbach, C.; Sekiguchi, K.; Semple, C. A. M.; Seno, S.; Sessa, L.; Sheng, Y.; Shibata, Y.; Shimada, H.; Shimada, K.; Silva, D.; Sinclair, B.; Sperling, S.; Stupka, E.; Sugiura, K.; Sultana, R.; Takenaka, Y.; Taki, K.; Tammoja, K.; Tan, S. L.; Tang, S.; Taylor, M. S.; Tegner, J.; Teichmann, S. A.; Ueda, H. R.; van Nimwegen, E.; Verardo, R.; Wei, C. L.; Yagi, K.; Yamanishi, H.; Zabarovsky, E.; Zhu, S.; Zimmer, A.; Hide, W.; Bult, C.; Grimmond, S. M.; Teasdale, R. D.; Liu, E. T.; Brusic, V.; Quackenbush, J.; Wahlestedt, C.; Mattick, J. S.; Hume, D. A.; Kai, C.; Sasaki, D.; Tomaru, Y.; Fukuda, S.; Kanamori-Katayama, M.; Suzuki, M.; Aoki, J.; Arakawa, T.; Iida, J.; Imamura, K.; Itoh, M.; Kato, T.; Kawaji, H.; Kawagashira, N.; Kawashima, T.; Kojima, M.; Kondo, S.; Konno, H.; Nakano, K.; Ninomiya, N.; Nishio, T.; Okada, M.; Plessy, C.; Shibata, K.; Shiraki, T.; Suzuki, S.;
Tagami, M.; Waki, K.; Watahiki, A.; Okamura-Oho, Y.; Suzuki, H.; Kawai, J.; Hayashizaki, Y. The Transcriptional Landscape of the Mammalian Genome. Science 2005, 309, 1559-1563.

9. Mehler, M. F.; Mattick, J. S. Noncoding RNAs in the Nervous System. J. Physiol. 2006, 575, 333-341.

10. Aravin, A. A.; Hannon, G. J.; Brennecke, J. The Piwi-piRNA Pathway Provides an Adaptive Defense in the Transposon Arms Race. Science 2007, 318, 761-764

11. Ku, G.; McManus, M. Y. Behind the Scenes of a Small RNA GeneSilencing Pathway. Hum. Gene Ther. 2008, 19, 17-26.

12. Chiu, Y. L.; Rana, T. M. SiRNA Function in RNAi: A Chemical Modification Analysis. RNA 2003, 9, 1034-1048.

13. Manoharan, M. RNA Interference and Chemically Modified Small Interfering RNAs. Curr. Opin. Chem. Biol. 2004, 8, 570-579.

14. Singh, S. K.; Nielsen, P.; Koshkin, A. A.; Wengel, J. LNA (Locked Nucleic Acids): Synthesis and High-Affinity Nucleic Acid Recognition. Chem. Commun. 1998, 4, 455-456.

15. Koshkin, A. A.; Singh, S. K.; Nielsen, P.; Rajwanshi, V. K.; Kumar, R.; Meldgaard, M.; Olsen, C. E.; Wengel, J. LNA (Locked Nucleic Acids): Synthesis of the Adenine, Cytosine, Guanine, 5-Methylcytosine, Thymine, and Uracil Bicyclonucleoside Monomers, Oligomerization, and Unprecedented Nucleic Acid Recognition. Tetrahedron 1998, 54(14), 3607-3630.

16. Mouritzen, P.; Nielsen, A. T.; Pfundheller, H. M.; Choleva, Y.; Kongsbak, L.; Moller, S. Single Nucleotide Polymorphism Genotyping Using Locked Nucleic Acid (LNA). Expert Rev. Mol. Diagn. 2003, 3(1), 27-38.

17. Crinelli, R.; Bianchi, M.; Gentilini, L.; Magnani, M. Design and Characterization of Decoy Oligonucleotides Containing Locked Nucleic Acids. Nucleic Acids Res. 2002, 30(11),2435-2443.

18. Childs, J. L.; Disney, M. D.; Turner, D. H. Oligonucleotide Directed Misfolding of RNA Inhibits Candida Albicans Group I Intron Splicing. Proc. Natl. Acad. Sci. U.S.A. 2002, 99(17), 11091-11096.

19. Wu, Y. R.; Yang, C. J.; Moroz, L. L.; Tan, W. H. Nucleic Acid Beacons for Long-Term Real-Time Intracellular Monitoring. Anal. Chem. 2008, 80(8), 3025-3028.

20. Goldman, S. R.; Ebright, R. H.; Nickels, B. E. Direct Detection of Abortive RNA Transcripts In Vivo. Science 2009, 324(5929), 927-928.

21. Mook, O. R.; Baas, F.; de Wissel, M. B.; Fluiter, K. Evaluation of Locked Nucleic Acid-Modified Small Interfering RNA In Vitro and In Vivo. Mol. Cancer Ther. 2007, 6(3), 833-843.

22. Darfeuille, F.; Hansen, J. B.; Orum, H.; Di Primo, C.; Toulme, J. J. LNA/DNA Chimeric Oligomers Mimic RNA Aptamers Targeted to the TAR RNA Element of HIV-1. Nucleic Acids Res. 2004, 32(10), 3101-3107.

23. Elmen, J.; Lindow, M.; Schutz, S.; Lawrence, M.; Petri, A.; Obad, S. Lindholm, M.; Hedtjarn, M.; Hansen, H. F.; Berger, U.; Gullans, S.; Kearney, P.; Sarnow, P.; Straarup, E. M.; Kauppinen, S. LNA-Mediated MicroRNA Silencing in Non-Human Primates. Nature 2008, 452(7189), 896-899

24. Rapozzi, V.; Cogoi, S.; Xodo, L. E. Antisense Locked Nucleic Acids Efficiently Suppress BCR/ABL and Induce Cell Growth Decline and Apoptosis in Leukemic Cells. Mol. Cancer Ther. 2006, 5(7), 1683-1692.

25. Jepsen, J. S.; Wengel, J. LNA-Antisense Rivals siRNA for Gene Silencing. Curr. Opin. Drug Discov. 2004, 7(2), 188-194.

26. Kauppinen, S.; Vester, B.; Wengel, J. Locked Nucleic Acid (LNA): High Affinity Targeting of RNA for Diagnostics and Therapeutics. Drug Discov. Today 2005, 2(3), 287-290.

27. Beverly, M.; Hartsough, K.; Machemer, L. Liquid Chromatography/ Electrospray Mass Spectrometric Analysis of Metabolites from an Inhibitory RNA Duplex. Rapid Commun. Mass Spectrom. 2005, 19(12), 1675-1682.

28. Zou, Y.; Tiller, P.; Chen, I. W.; Beverly, M.; Hochman, J. Metabolite Identification of Small Interfering RNA Duplex by High-Resolution Accurate Mass Spectrometry. Rapid Commun. Mass Spectrom. 2008, 22(12), 1871-1881.

29. Farand, J.; Beverly, M. Sequence Confirmation of Modified Oligonucleotides Using Chemical Degradation, Electrospray Ionization, Time-ofFlight, and Tandem Mass Spectrometry. Anal. Chem. 2008, 80(19), $7414-7421$

30. Farand, J.; Gosselin, F. De Novo Sequence Determination of Modified Oligonucleotides. Anal. Chem. 2009, 81(10), 3723-3730.

31. McLuckey, S. A.; Habibigoudarzi, S. Ion-Trap Tandem Mass Spectrometry Applied to Small Multiply-Charged Oligonucleotides with a Modified Base. J. Am. Soc. Mass Spectrom. 1994, 5(8), 740-747.

32. Tromp, J. M.; Schürch, S. Gas-Phase Dissociation of Oligoribonucleotides and their Analogues Studied by Electrospray Ionization Tandem Mass Spectrometry. J. Am. Soc. Mass Spectrom. 2005, 16, 1262-1268.

33. Flora, J. W.; Muddiman, D. C. Complete Sequencing of MonoDeprotonated Peptide Nucleic Acids by Sustained Off-Resonance Irradiation Collision-Induced Dissociation. Rapid Commun. Mass Spectrom. 2001, 12(7), 805-809.

34. Huang, T.-Y.; Liu, J.; Liang, X.; Hodges, B. D. M.; McLuckey, S. A Collision-Induced Dissociation of Intact Duplex and Single-Stranded siRNA Anions. Anal. Chem. 2008, 80, 8501-8508.

35. Greig, M.; Griffey, R. M. Utility of Organic Bases for Improved Electrospray Mass Spectrometry of Oligonucleotides. Rapid Commun. Mass Spectrom. 1995, 9, 97-102.

36. Xia, Y.; Chrisman, P. A.; Erickson, D. E.; Liu, J.; Liang, X.; Londry, F. A.; Yang, M. J.; McLuckey, S. A. Implementation of Ion/Ion Reactions in a Quadrupole/Time-of-Flight Tandem Mass Spectrometer. Anal. Chem. 2006, 78(12), 4146-4154. 
37. Xia, Y.; Liang, X.; McLuckey, S. A. Pulsed Duel Electrospray Ionization for Ion/Ion Reactions. J. Am. Soc. Mass Spectrom. 2005, 16, 1750-1756.

38. McTigue, P. M.; Peterson, R. J.; Kahn, J. D. Sequence-Dependent Thermodynamic Parameters for Locked Nucleic Acid (LNA)-DNA Duplex Formation. Biochemistry 2004, 43(18), 5388-5405.

39. McLuckey, S. A.; Van Berkel, G. J.; Glish, G. L. Mass Spectrometry/ Mass Spectrometry of Small Multiply Charged Oligonucleotides. J. Am. Soc. Mass Spectrom. 1992, 3, 60-70.

40. Wu, J.; McLuckey, S. A. Gas-Phase Fragmentation of Oligonucleotide Ions. Int. J. Mass Spectrom. 2004, 237, 197-241.

41. Schürch, S.; Bernal-Mendez, E.; Leumann, C. J. Electrospray Tandem Mass Spectrometry of Mixed-Sequence RNA/DNA Oligonucleotides. J. Am. Soc. Mass Spectrom. 2002, 13, 936-945.

42. Andersen, T. E.; Kirpekar, F.; Haselmann, K. F. RNA Fragmentation in MALDI Mass Spectrometry Studied by H/D-Exchange: Mechanisms of General Applicability to Nucleic Acids. J. Am. Soc. Mass Spectrom. 2006, 17, 1353-1368.

43. McLuckey, S. A.; Habibi-Goudarzi, S. Decompositions of MultiplyCharged Oligonucleotide Anions. J. Am. Chem. Soc. 1993, 115, 1208512095
44. McLuckey, S. A.; Vaidyanathan, G.; Habibi-Goudarzi, S. Charged vs Neutral Nucleobase Loss from Multiply Charged Oligonucleotide Anions. J. Mass Spectrom. 1995, 30, 1222-1229.

45. Huang, T. -Y.; Kharlamova, A.; Liu, J.; McLuckey, S. A. Ion Trap Collision-Induced Dissociation of Multiply Deprotonated RNA: c/yIons Versus (a-B)/w-Ions. J. Am. Soc. Mass Spectrom. 2008, 19(12), $1832-1840$

46. Wang, Z.; Wan, K. X.; Ramanathan, R.; Taylor, J. S.; Gross, M. L Structure and Fragmentation Mechanisms of Isomeric T-Rich Oligodeoxynucleotides: A Comparison of Four Tandem Mass Spectrometric Methods. J. Am. Soc. Mass Spectrom. 1998, 9, 683-691.

47. Wan, K. X.; Gross, J.; Hillenkamp, F.; Gross, M. L. Fragmentation Mechanisms of Oligodeoxynucleotides Studied by H/D Exchange and Electrospray Ionization Tandem Mass Spectrometry. J. Am. Soc. Mass Spectrom. 2001, 12, 193-205.

48. Wan, K. X.; Gross, M. L. Fragmentation Mechanisms of Oligodeoxynucleotides: Effects of Replacing Phosphates with Methylphosphonates and Thymines with Other Bases in T-Rich Sequences. J. Am. Soc. Mass Spectrom. 2001, 12, 580-589. 